BMJ Open

Diabetes

Research

\& Care

\title{
Medication-induced hyperglycemia: pediatric perspective
}

\author{
Mustafa Tosur (1) , Johanna Viau-Colindres, Marcela Astudillo, \\ Maria Jose Redondo, Sarah K Lyons
}

To cite: Tosur M, Viau-Colindres J, Astudillo M, et al. Medicationinduced hyperglycemia: pediatric perspective. BMJ Open Diab Res Care 2020;8:e000801. doi:10.1136/ bmjdrc-2019-000801

MT and JV-C are joint first authors.

Received 15 August 2019 Revised 27 September 2019 Accepted 23 October 2019

Check for updates

\section{(c) Author(s) (or their} employer(s)) 2020. Re-use permitted under CC BY-NC. No commercial re-use. See rights and permissions. Published by BMJ.

Department of Pediatrics, Section of Diabetes and Endocrinology, Baylor College of Medicine, Houston, Texas, USA

Correspondence to Dr Mustafa Tosur; mustafa.tosur@bcm.edu

\section{ABSTRACT}

Medication-induced hyperglycemia is a frequently encountered clinical problem in children. The intent of this review of medications that cause hyperglycemia and their mechanisms of action is to help guide clinicians in prevention, screening and management of pediatric drug-induced hyperglycemia. We conducted a thorough literature review in PubMed and Cochrane libraries from inception to July 2019. Although many pharmacotherapies that have been associated with hyperglycemia in adults are also used in children, pediatric-specific data on medication-induced hyperglycemia are scarce. The mechanisms of hyperglycemia may involve $\beta$ cell destruction, decreased insulin secretion and/or sensitivity, and excessive glucose influx. While some medications (eg, glucocorticoids, L-asparaginase, tacrolimus) are markedly associated with high risk of hyperglycemia, the association is less clear in others (eg, clonidine, hormonal contraceptives, amiodarone). In addition to the drug and its dose, patient characteristics, such as obesity or family history of diabetes, affect a child's risk of developing hyperglycemia. Identification of pediatric patients with increased risk of developing hyperglycemia, creating strategies for risk reduction, and treating hyperglycemia in a timely manner may improve patient outcomes.

\section{INTRODUCTION}

Euglycemia is a tightly controlled state regulated by the interplay of multiple hormones that balance glucose production and clearance. Among the hormones, insulin has the strongest effect on glucose metabolism. Several medications impair the production, secretion, or action of insulin and thus may lead to drug-induced hyperglycemia. Although the incidence of drug-induced hyperglycemia in children is unknown, with the advent of new medications that are known to cause hyperglycemia, it is expected to be on the rise. Drug-induced hyperglycemia increases the burden of care of patients and is associated with less favorable outcomes such as cardiovascular disease, diabetic emergencies and premature death. ${ }^{12}$

The objective of this review is to identify and describe the drugs that can cause hyperglycemia, with an emphasis on the pediatric population. Because of acute and long-term complications of hyperglycemia, it is critically important for pediatricians to recognize medications' role in causing hyperglycemia, be familiar with the mechanism of actions, and develop strategies to minimize its frequency and related complications.

\section{METHODS}

We conducted a bibliographic search in PubMed and Cochrane Library databases from inception to July 2019 using the keywords drug induced diabetes, drug induced hyperglycemia, medication induced diabetes, and medication induced hyperglycemia. We also searched by hyperglycemia and the specific medications/medication classes that have been associated with hyperglycemia ( $g l u c o-$ corticoids, L-asparaginase, calcineurin inhibitors, tacrolimus, cyclosporine, the mammalian target of rapamycin (mTOR) inhibitors, sirolimus, basiliximab, nivolumab/pembrolizumab, valproic acid, phenytoin, clonidine, $\alpha$-agonists, atypical antipsychotics, thiazides, $\beta$-blockers, amiodarone, prostaglandin E1 (PGE1), statins, niacin, growth hormone, hormonal contraceptives, octreotide, somatostatin, diazoxide, $\beta$-2-agonists, albuterol, salmeterol, salbuterol, theophylline, fluoroquinolones, pentamidine, protease inhibitors, nucleoside reverse transcriptase inhibitors, didanosine, and parenteral nutrition). The search was limited to human studies including case reports published in English. Both pediatric and adult studies were retrieved. In addition to the database search, the reference lists in retrieved articles were checked manually. For many of the medications described in this review, evidence comes from case reports or extrapolations of adult data.

\section{MECHANISIMS OF HYPERGLYCEMIA}

Mechanisms involved in medication-induced hyperglycemia include $\beta$ cell destruction, decreased insulin secretion and/or sensitivity, and excessive glucose influx (figure 1). The majority of drugs associated with 


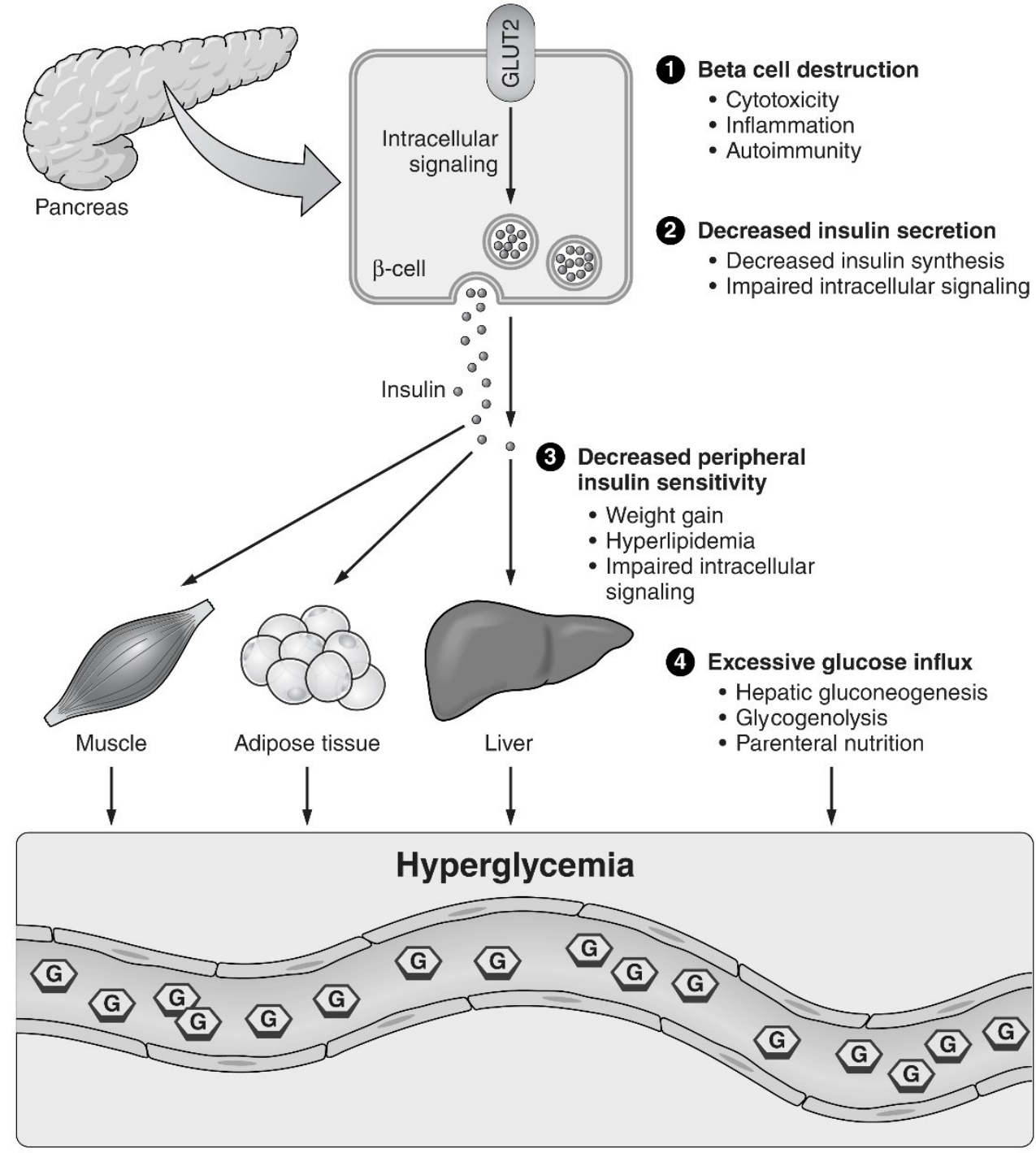

Figure 1 Proposed mechanisms of medication-induced hyperglycemia.

hyperglycemia affect insulin production, secretion, or action, leading to an imbalance in insulin and glucose homeostasis.

\section{$\beta$ cell destruction}

$\beta$ cells can be destroyed by multiple mechanisms including direct cytotoxicity on pancreatic $\beta$ cells, inflammation, and islet autoimmunity. Evidence on increased islet cell autoimmunity with certain medications has been emerging. Many pharmacotherapies, particularly newer anticancer medications, modulate immune checkpoint proteins, modify $\mathrm{T}$ cell regulatory function, and increase the risk of immune-mediated endocrinopathies, including diabetes mellitus. ${ }^{1}$

\section{Decreased insulin secretion}

Hyperglycemia induces a series of intracellular signals that result in the release of insulin secretory granules that were previously synthesized, processed and stored. Medications that affect the body's ability to adequately synthesize and secrete insulin result in hyperglycemia. ${ }^{3}$

\section{Decreased peripheral insulin sensitivity}

When insulin reaches target tissues, it binds to a cell membrane receptor that induces a conformational change and activation of intracellular signals. This results in inhibition of glycogenolysis and gluconeogenesis, increased glucose transport to fat and muscle tissue, and stimulation of glycogen synthesis. Drugs that reduce the receptor number or affinity, interfere with insulin action, or inhibit postreceptor events can cause hyperglycemia by decreasing insulin sensitivity. In addition, some drugs decrease insulin sensitivity in target tissues through indirect mechanisms such as weight gain, leading to obesityinduced insulin resistance. ${ }^{4}$

\section{Excessive glucose influx}

There are several physiologic processes that release glucose into the circulation (eg, hepatic glycogenolysis, hepatic gluconeogenesis) while others (eg, glycogen synthesis) remove glucose. Medications that enhance glycogenolysis or gluconeogenesis may result 
in hyperglycemia. In addition, excessive glucose intake, particularly through a parenteral route, may overwhelm the pancreatic capacity of insulin production and cause hyperglycemia. ${ }^{5}$

\section{Multihit hypothesis}

Hyperglycemia does not occur in all individuals exposed to diabetogenic drugs but it is more common when several factors are involved, including: (1) Host-specific factors such as obesity, insulin resistance or $\beta$ cell autoimmunity. (2) High doses of diabetogenic medications or multiple medications that affect glucose metabolism (ie, additive effect). (3) Environmental influences (eg, diet, stress, illness, lack of physical activity).

For some medications, efforts directed at identifying individuals at risk of developing drug-induced hyperglycemia are hindered by its sporadic occurrence. Conversely, risk factors have been better described in patient populations and for medications associated with a higher incidence of hyperglycemia. For example, among children with acute lymphoblastic leukemia (ALL), those with older age, obesity, and family history of diabetes have higher probability of developing hyperglycemia. ${ }^{6}$

\section{MEDICATIONS ASSOCIATED WITH HYPERGLYCEMIA}

Medications associated with hyperglycemia are summarized in table 1 and detailed below:

\section{Glucocorticoids}

In the pediatric population, glucocorticoids are widely used to treat numerous conditions, such as asthma, rheumatologic conditions, hematologic malignancies, and post-transplant immunosuppressive regimens. While glucocorticoids are therapeutic for the underlying condition, hyperglycemia is a common adverse effect.

The pathophysiology of glucocorticoid-induced hyperglycemia involves multiple mechanisms: increased insulin resistance, increased gluconeogenesis, and decreased insulin production. ${ }^{7}$ Glucocorticoids inhibit appetite suppression leading to increased weight gain and insulin resistance. They increase hepatic gluconeogenesis by activating genes coding for phosphoenol-pyruvatecarboxykinase and glucose-6-phosphatase, and by upregulating the effects of the counter-regulatory hormones including glucagon and epinephrine.

Although all glucocorticoid compounds and routes of administration may result in hyperglycemia, systemic administration, higher doses, and a long duration of treatment are more likely to be associated with it. ${ }^{7}$ In adults, older age, history of glucose intolerance and family history of diabetes have been associated with development of hyperglycemia. In children, although some host risk factors have been identified, these are less well understood.

The frequency of hyperglycemia associated with glucocorticoids in children is difficult to establish. Glucocorticoids are used in a myriad of conditions making the population heterogeneous. Second, as the patients' clinical condition evolves, often, different compounds, routes of administration, schedules, and doses are used. In addition, other medications, stress, inflammation, and underlying $\beta$ cell dysfunction may have additive effects. Finally, with a few exceptions, hyperglycemia is poorly documented as priority is given to the condition that required the use of steroids. ${ }^{67}$

\section{Antineoplastic and immunomodulatory drugs L-asparaginase}

L-asparaginase is a part of the standard treatment for ALL as it depletes available asparagine in leukemic cells, leading to cell death. ${ }^{8}$ Insulin synthesis is also dependent on asparagine, making hyperglycemia one of the most common side effects of the medication. Other mechanisms involved in L-asparaginase-induced hyperglycemia may include $\beta$ cell dysfunction secondary to pancreatitis, impairment in insulin receptor function, and hyperglucagonemia. Because it induces an insulinopenic state, acute hyperglycemic complications such as diabetic ketoacidosis and hyperosmolar non-ketotic state can occur. ${ }^{9}$

\section{Calcineurin inhibitors: tacrolimus and cyclosporine}

Calcineurin inhibitors are a group of immunosuppressant medications commonly used in autoimmune disorders and after solid organ transplants. These drugs block $\mathrm{T}$ cell mediated immune response by inhibiting calcineurin phosphatase activity. However, calcineurin is widely distributed in other tissues including the pancreas, and thus its use has been associated with hyperglycemia. The mechanism for hyperglycemia is multifactorial but, at least in vivo, it is explained by impaired insulin secretion which is affected at multiple points, from mRNA transcription to post-translational modification. ${ }^{3}$

The hyperglycemic effect from calcineurin inhibitors exhibits significant patient variability. The effect is dose-dependent and medication-dependent. Compared with cyclosporine, tacrolimus has been associated with higher rates of hyperglycemia, likely from differential tissue concentration of their binding proteins: tacrolimus binding protein is highly concentrated in the pancreatic $\beta$ cells, while cyclosporine binding protein is preferentially located in the heart, liver and kidney. ${ }^{10}$ In a study of 229 children with post-transplant diabetes mellitus, the OR of diabetes with tacrolimus use was 9.1 compared with cyclosporine use. ${ }^{11}$

\section{mTOR inhibitors: sirolimus}

Sirolimus, also known as rapamycin, is an inhibitor of mTOR and is used as a potent immunosuppressant posttransplantation. The mTOR pathway is important for insulin secretion and sensitivity. ${ }^{12}$ Sirolimus decreases insulin production through a direct effect on the proliferation and insulin production of the $\beta$ cells, and increases insulin resistance by affecting intracellular signaling. ${ }^{12}$ The risk of new-onset diabetes was over $60 \%$ higher in kidney transplant adult recipients taking sirolimus in combination with cyclosporine compared with those 
Table 1 Medications associated with hyperglycemia by medication groups

\begin{tabular}{ll}
\hline Drug class & Sample agents \\
\hline Anti-inflammatory, antineoplastic and immunomodulatory drug & Hydrocortisone \\
Glucocorticoids & Prednisone \\
& Dexamethasone
\end{tabular}

Proposed mechanisms for hyperglycemia

\begin{tabular}{|c|c|c|}
\hline L-asparaginase & L-asparaginase & $\begin{array}{l}\text { Decreased insulin synthesis } \\
\beta \text { cell damage } \\
\text { Impairment in insulin receptor function } \\
\text { Hyperglucagonemia }\end{array}$ \\
\hline Calcineurin inhibitor & $\begin{array}{l}\text { Tacrolimus } \\
\text { Cyclosporine }\end{array}$ & Decreased insulin secretion \\
\hline mTOR inhibitors & Sirolimus & $\begin{array}{l}\text { Decreased insulin secretion } \\
\text { Increased insulin resistance }\end{array}$ \\
\hline Monoclonal antibody & Basiliximab & Increased islet autoimmunity \\
\hline Checkpoint inhibitors & Nivolumab and pembrolizumab & Increased islet autoimmunity \\
\hline \multicolumn{3}{|l|}{ Veurologic and psychiatric drugs } \\
\hline$\gamma$ aminobutyric acid Inhibitors & Valproic acid & $\begin{array}{l}\text { Weight gain } \\
\text { Increased insulin resistance }\end{array}$ \\
\hline Voltage gated sodium channel blockers & Phenytoin & $\begin{array}{l}\text { Decreased insulin secretion } \\
\text { Increased insulin resistance }\end{array}$ \\
\hline$\alpha$-2-adrenergic agonists & Clonidine & Decreased insulin secretion \\
\hline Atypical antipsychotics & $\begin{array}{l}\text { Quetiapine } \\
\text { Olanzapine } \\
\text { Risperidone } \\
\text { Aripiprazole } \\
\text { Ziprasidone }\end{array}$ & $\begin{array}{l}\text { Increased insulin resistance } \\
\text { Weight gain } \\
\text { Decreased insulin secretion }\end{array}$ \\
\hline \multicolumn{3}{|l|}{ Sardiovascular and renal drugs } \\
\hline Thiazide diuretics & Multiple & $\begin{array}{l}\text { Increased insulin resistance } \\
\text { Decreased insulin secretion }\end{array}$ \\
\hline$\beta$-blockers & Multiple & $\begin{array}{l}\text { Decreased insulin secretion } \\
\text { Increased insulin resistance }\end{array}$ \\
\hline Class III antiarrhythmics & Amiodarone & Unknown \\
\hline Prostaglandins & PGE 1 & $\begin{array}{l}\text { Decreased insulin secretion } \\
\text { Increased glucagon secretion }\end{array}$ \\
\hline HMG-CoA reductase inhibitors (statins) & Multiple & $\begin{array}{l}\text { Increased insulin resistance } \\
\text { Decreased insulin secretion }\end{array}$ \\
\hline Vitamin $\mathrm{B}_{3}$ & Niacin & $\begin{array}{l}\text { Increased glucose production } \\
\text { Increased insulin resistance }\end{array}$ \\
\hline \multicolumn{3}{|l|}{ Endocrinologic drugs } \\
\hline Growth hormone & Growth hormone & $\begin{array}{l}\text { Increased insulin resistance } \\
\text { Increased gluconeogenesis }\end{array}$ \\
\hline Hormonal contraceptives & Multiple & $\begin{array}{l}\text { Decreased insulin secretion } \\
\text { Increased insulin resistance }\end{array}$ \\
\hline Somatostatin analogs & $\begin{array}{l}\text { Octreotide } \\
\text { Pasireotide }\end{array}$ & Decreased insulin secretion \\
\hline Potassium channel activator & Diazoxide & Decreased insulin secretion \\
\hline
\end{tabular}

Increased insulin resistance Increased gluconeogenesis Decreased insulin production Weight gain Upregulation of the effect of glucagon and epinephrine

Decreased insulin synthesis damage Hyperglucagonemia

Decreased insulin secretion ncreased insulin resistance Increased islet autoimmunity Increased islet autoimmunity

Weight gain Increased insulin resistance ncreased insulin resistance

Increased insulin resistance Weight gain

Olanzapine

Aripiprazole

Increased insulin resistance Decreased insulin secretion

Decreased insulin secretion Increased insulin resistance

Decreased insulin secretion secretion

Increased insulin resistance Increased glucose production 
Table 1 Continued

\begin{tabular}{lll}
\hline Drug class & Sample agents & Proposed mechanisms for hyperglycemia \\
\hline Fluoroquinolones & $\begin{array}{l}\text { Ciprofloxacin } \\
\text { Gemifloxacin } \\
\text { Levofloxacin } \\
\text { Moxifloxacin } \\
\text { Ofloxacin }\end{array}$ & Decreased insulin secretion \\
\hline $\begin{array}{l}\text { Antiprotozoals } \\
\text { Antifungals }\end{array}$ & Pentamidine & \\
\hline $\begin{array}{l}\text { Protease inhibitors } \\
\text { Nucleoside reverse transcriptase }\end{array}$ & $\begin{array}{l}\text { Ritonavir } \\
\text { Nelfinavir } \\
\text { Indinavir }\end{array}$ & Decreased insulin secretion \\
Respiratory drugs & Abacavir & Decreased insulin secretion \\
Increased insulin resistance
\end{tabular}

HMG-CoA, 3-hydroxy-3-methyl-glutaryl-coenzyme A; mTOR, mammalian target of rapamycin; PGE1, prostaglandin 1.

treated with cyclosporine combined with other immunosuppressive agents (ie, mycophenolate mofetil or azathioprine). ${ }^{13}$ However, hyperglycemic effect of sirolimus appers to be significantly less than that of tacrolimus as improvement in hyperglycemia shown in patients who were switched from tacrolimus to sirolimus. ${ }^{14}$

\section{Monoclonal antibody against IL-2: basiliximab}

Basiliximab is a recombinant monoclonal antibody against interleukin (IL) 2 receptor that is used to prevent acute rejection in kidney transplant patients. Since IL-2 is also required for the maintenance of immunologic self-tolerance through natural $\mathrm{T}$ regulatory cells, basiliximab may increase the risk of autoimmune diseases, including type 1 diabetes (T1D) ${ }^{15}$ Increased rate of newonset diabetes after kidney transplant was shown in adult patients who had induction with a regimen that included basiliximab ${ }^{16}$ However, since basiliximab is usually used for a short period of time and in combination with other diabetogenic agents, additional studies are needed to assess its clinical significance. There are no reports of hyperglycemia associated with basiliximab in children.

\section{Immune checkpoint inhibitors: nivolumab and pembrolizumab}

Nivolumab and pembrolizumab are monoclonal antibodies against programmed cell death protein 1 (PD1) (anti-PD1) used in treatment of a variety of malignancies such as malignant melanoma, lymphoma, and renal and lung cancers. ${ }^{1}$ The number of new-onset T1D cases in patients treated with anti-PD1 therapy has been increasing. ${ }^{17}$ Diabetic ketoacidosis and severe hyperglycemia were common initial presentations in these patients. Although the exact mechanism of action is unknown, the effect of anti-PD1 therapy on T cell regulatory function is thought to play a role in development of autoimmune diabetes. There are no reports of T1D associated with anti-PD1 therapy in children.

\section{Neurologic and psychiatric drugs}

\section{Antiepileptics}

Valproic acid is a broad-spectrum antiepileptic and mood stabilizer that increases the bioavailability of $\gamma$ aminobutyric acid to brain neurons. Its use is associated with hyperglycemia, dyslipidemia, and hyperuricemia. ${ }^{4}$ The mechanism of hyperglycemia is postulated to be associated with weight gain. Valproic acid-induced weight gain might be related to the modulator effect of valproic acid on multiple neurotransmitters involved in appetite and satiety, including leptin, neuropeptide $\mathrm{Y}$, ghrelin and adiponectin. In a study of 114 children with epilepsy treated with valproic acid monotherapy, $40 \%$ developed obesity and $45 \%$ had evidence of impaired glucose homeostasis after 2 years of treatment. ${ }^{18}$

Phenytoin is an antiepileptic drug that prolongs the effective refractory period by decreasing influx of sodium ions across the cell membranes. Hyperglycemia has been described in several pediatric cases of phenytoin toxicity, but resolved when levels were no longer supratherapeutic. The two proposed mechanisms for phenytoininduced hyperglycemia are inhibition of insulin release and increased insulin resistance. ${ }^{19} 20$

\section{Clonidine}

Clonidine is an $\alpha$-2-adrenergic agonist, approved for treatment of attention-deficit hyperactivity disorder in children and hypertension in adults. It is also used off-label for oppositional defiant disorder and Tourette syndrome. Its use has been associated with hyperglycemia, likely from stimulation of the $\alpha$ receptors in the pancreatic $\beta$ cells leading to inhibition of insulin secretion. ${ }^{21}$ However, 
clinically, clonidine can cause two opposite effects: worsening of hyperglycemia, likely secondary to inhibition of insulin secretion; and attenuation of hyperglycemia, likely from inhibition of cortisol and catecholamines. ${ }^{21} 22$

\section{Atypical antipsychotics}

Atypical or second-generation antipsychotics, such as olanzapine, clozapine, risperidone and quetiapine, block dopamine D2 receptors in the brain. Compared with the first-generation antipsychotics, these have less extrapyramidal side effects but have higher rates of metabolic disturbances, including hyperglycemia. ${ }^{23}$ Proposed mechanisms for hyperglycemia include increased insulin resistance secondary to weight gain and direct peripheral effects, and decreased insulin secretion due to direct effect on pancreatic $\beta$ cells. ${ }^{24}$

Hyperglycemia associated with atypical antipsychotics is not uncommon. A retrospective study of more than 28 000 patients aged 6-24 years receiving atypical antipsychotics and 14000 controls showed a three-fold risk of developing hyperglycemia in the patients using atypical antipsychotics. ${ }^{25}$

\section{Cardiovascular and renal drugs \\ Thiazide diuretics}

Thiazides are commonly prescribed diuretics. In adults, their use can be associated with metabolic adverse events, including hyperglycemia, hyperlipidemia, hypokalemia and hyperuricemia. ${ }^{26}$ However, hyperglycemia has not been reported in children.

Proposed mechanisms for hyperglycemia include increased insulin resistance and inhibition of glucosemediated insulin release. It is hypothesized that hypokalemia may be responsible, at least in part, for some of these abnormalities through different mechanisms: hyperpolarization of the cell membrane leading to the decreased insulin secretion, decreased blood perfusion to the muscle that causes decreased glucose uptake and increased insulin resistance. ${ }^{27}$

\section{$\beta$-blockers}

$\beta$-blockers are another group of antihypertensive drugs that have been associated with hyperglycemia. In a systematic review and meta-analysis of 94492 adult patients with hypertension, $\beta$-blockers were associated with $22 \%$ increased risk for new-onset diabetes. ${ }^{28}$ However, this effect has not been reported in the pediatric population. The mechanism of hyperglycemia is not well understood. Postulated mechanisms include inhibition of the $\beta$-2-adrenergic mediated first phase of insulin release, increased insulin resistance from weight gain, and decreased glucose uptake by muscles due to vasoconstriction. ${ }^{29}$

\section{Amiodarone}

Amiodarone is a class III antiarrhythmic. Most common side effects include thyroid dysfunction, liver dysfunction, and pulmonary fibrosis. However case reports of hyperglycemia have been reported both in the adult and pediatric literature..$^{30} 31$ The mechanism is unclear.

\section{Prostaglandin E1}

PGE1 is used in infants with ductus-dependent congenital cardiovascular disease. Under experimental conditions, PGE1 acutely inhibits insulin response to glucose and increases glucagon secretion. However, clinically this effect may not be relevant. There is only one case report of an infant who developed hyperglycemia while receiving a PGE1 infusion. ${ }^{32}$

\section{HMG-CoA reductase inhibitors}

Statins, or HMG-CoA (3-hydroxy-3-methyl-glutaryl-coenz yme A) reductase inhibitors, are commonly used in the treatment of dyslipidemia and prevention of cardiovascular disease. In adults, hyperglycemia is a well-described side effect of statins with adjusted ORs of 1.07 to 1.25 depending on the statin and dose. ${ }^{33}$ The mechanism of statin-induced hyperglycemia is unclear and postulated to be multifactorial. There is evidence of decreased insulin sensitivity as well as decreased insulin secretion in individuals treated with statin. ${ }^{34}$ However, pediatric studies have not reported an increased risk of hyperglycemia with statin use. A study of 60 children with T1D who were randomized to atorvastatin or placebo found no significant changes in hemoglobin A1c (HbAlc) or insulin sensitivity score at 6 months of therapy. ${ }^{35}$

\section{Niacin}

Niacin, or nicotinic acid, is another drug used for dyslipidemia that has been associated with hyperglycemia in adults. The mechanism of hyperglycemia is complex and involves increased hepatic gluconeogenesis and increased insulin resistance without adequate $\beta$ cell compensation. ${ }^{36}$ Risk factors for hyperglycemia include older age, prediabetes, and high doses of the medication. There are no reports in children.

\section{Endocrinologic drugs \\ Growth hormone}

Recombinant growth hormone is widely used for the treatment of growth hormone deficiency as well as other etiologies of short stature including Turner Syndrome, SHOX (short stature homeobox-containing gene) haploinsufficiency and small for gestational age infants without catch-up growth. Growth hormone antagonizes the effects of insulin on glucose and lipid metabolism, and causes insulin resistance. ${ }^{37}$

In a study of over 23000 children, growth hormone treatment was found to increase the risk of type 2 diabetes (T2D) development by six-fold but there was no effect on T1D risk. ${ }^{38}$ However, the actual incidence of T2D was only 34.4 per 100000 years of growth hormone treatment. The majority of the cases involved were postpubertal patients who had other risk factors for diabetes, and resolution of diabetes after discontinuation of growth hormone treatment was not always seen. In children with T1D, treatment with growth hormone results in an increase in total 
daily insulin dose which confirms an effect in glucose metabolism independent of insulin secretion. ${ }^{39}$

\section{Hormonal contraceptives}

Hormonal contraceptives contain a progestin with or without estrogen. While estrogens are more strongly associated with insulin resistance, progestins may cause insulin resistance and prolonged insulin half-life. ${ }^{40}$ Depending on the progestin used and whether it is combined with estrogen, there are differences in glucose, insulin and $\mathrm{C}$ peptide levels in intravenous glucose tolerance tests. Progestin-only forms have the most favorable metabolic profile. In addition, the effect varies by route of delivery, with a lesser effect with transdermal routes compared with the oral route. A recent Cochrane systematic review reported that the alteration in glucose metabolism is clinically insignificant in women without diabetes. ${ }^{41}$

\section{Somatostatin analogs}

Octreotide and pasireotide are somatostatin analogs used for the treatment of acromegaly, neuroendocrine tumors and gastrointestinal bleeding. In pediatrics, they are also used (off-label) for chylothorax, persistent hyperinsulinemia and intractable diarrhea. Somatostatin analogs work primarily by inhibiting growth hormone release, but they also inhibit insulin and to a lesser extent, glucagon secretion. Therefore, dysglycemia is a known side effect, with hyperglycemia occurring more often than hypoglycemia. Due to this effect, octreotide is also used for treatment of hyperinsulinemic hypoglycemia and sulfonylurea intoxication. $^{42}$

The incidence of hyperglycemia varies considerably between reports. One study showed hyperglycemia in $1 / 1000$ infant-days in 428 infants receiving octreotide. ${ }^{43}$ However, two other studies have shown significantly higher rates of hyperglycemia: $45 \%$ in a series of 29 children who received octreotide for chylothorax, and $76 \%$ in a series of 34 children who received octreotide for chemotherapy-induced diarrhea. ${ }^{44}{ }^{45}$ There is no data available on hyperglycemic effect of pasireotide in the pediatric population.

\section{Anti-infectives \\ Antibiotics: fluoroquinolones}

Fluoroquinolones are a group of broad-spectrum antibiotics commonly used in adults. Although not first-line treatment in pediatrics, they are used in complicated urinary tract infections, respiratory infections associated with cystic fibrosis, and multidrug-resistant bacteremia. A common side effect is dysglycemia, with hyperglycemia occurring more often than hypoglycemia. The mechanism for hyperglycemia is poorly understood but likely involves decreased insulin secretion. ${ }^{46}$

The incidence of hyperglycemia varies depending on the compound used. The highest incidence was seen with gatifloxacin, prompting its voluntary withdrawal from the US market in $2006 .{ }^{47}$ Data in children are limited to a single pediatric study which showed no association between dysglycemia and gatifloxacin treatment in Vietnamese children treated with fluoroquinolones. ${ }^{48}$

\section{Antiprotozoals: pentamidine}

Pentamidine is an antiprotozoal agent used for prophylaxis and treatment of Pneumocystis jirovecii infection. It has been associated with both hypoglycemia and hyperglycemia. The postulated mechanism for dysglycemia is direct cytotoxic damage to the $\beta$ cells. In the initial phase of this process, insulin is released resulting in hypoglycemia; in the latter phase, direct $\beta$ cell toxicity occurs resulting in insufficient insulin secretion and hyperglycemia. ${ }^{49}$ In a study of 128 adult patients on pentamidine, 48 (38\%) developed dysglycemia: 7 hypoglycemia, 18 hypoglycemia followed by diabetes, and 23 diabetes alone. ${ }^{50}$ More than half of the patients who developed hyperglycemia required insulin and had low $\mathrm{C}$ peptide levels supporting insulinopenia as the causative mechanism. There is only one pediatric case report on pentamidine-induced hyperglycemia. ${ }^{51}$

\section{Antiretrovirals}

Protease inhibitors (eg, ritonavir, nelfinavir, indinavir) are common components of HIV therapeutic regimens. Hyperglycemia can occur with any of these agents, presenting either as new-onset diabetes or worsening control in patients with diabetes. The mechanism of hyperglycemia is thought to be associated with increased insulin resistance and decreased insulin secretion secondary to $\beta$ cell dysfunction. ${ }^{52}$

In adult patients with HIV receiving protease inhibitors, incidences of impaired glucose tolerance and diabetes were reported as high as $46 \%$ and $13 \%$, respectively. ${ }^{53}$ In the Pediatric HIV/AIDS Cohort Study, amprenavir use was independently associated with a fourfold greater odds of insulin resistance with no incident diabetes cases in 402 children. ${ }^{54}$

To a lesser extent, therapy with nucleoside reverse transcriptase inhibitors didanosine and abacavir may also result in hyperglycemia. The mechanism may involve mitochondrial toxicity resulting in apoptosis of peripheral adipocytes, lipoatrophy and hypertriglyceridemia. ${ }^{55}$

\section{Respiratory drugs \\ $\beta$-2-agonists}

$\beta$-2-agonists are commonly used in asthma, cystic fibrosis, and chronic lung disease. Activation of $\beta$-2-receptors may lead to hyperglycemia via hepatic and muscle glycogenolysis and gluconeogenesis. ${ }^{56}$ In healthy controls and in patients with diabetes, systemic administration of $\beta$ agonists has been clearly associated with hyperglycemia. However, the hyperglycemic effect of inhaled $\beta$-2agonists, is less clear.

Studies in children are limited. A study of 12 children with acute asthma exacerbation showed that at high dose, nebulized salbutamol resulted in a significant increase in blood glucose.$^{57}$ Another study of 10 adolescents and young adults with T1D and 9 with cystic fibrosis related 
diabetes showed inhaled albuterol did not result in significant increase in blood glucose in either group compared with placebo. ${ }^{58}$

\section{Theophylline}

Theophylline is a phosphodiesterase inhibitor used for chronic lung disease and severe asthma exacerbations. Its toxicity has been associated with multiple metabolic abnormalities, including hyperglycemia. Hyperglycemia is hypothesized to be caused by increased catecholamines as it can be partially reversed with $\beta$ blockade. ${ }^{59}$

In pediatrics, all reported cases have been at supratherapeutic levels of theophylline. However, supratherapeutic levels are not uncommon as theophylline has a narrow therapeutic window, along with erratic absorption and elimination. In a pediatric case series of 125 patients with theophylline intoxication, $89 \%$ had hyperglycemia. ${ }^{60}$

\section{Nutritional}

Parenteral nutrition

Although not a medication per se, parenteral nutrition is often associated with hyperglycemia in both inpatient and outpatient settings. The mechanism underlying parenteral nutrition associated hyperglycemia is complex and involves supraphysiologic glucose infusion rates and excessive delivery of gluconeogenic substrates that overwhelm the pancreatic capacity of insulin production. ${ }^{5}$ In addition, the patients receiving parenteral nutrition often have increased hepatic glucose production and reduced peripheral glucose utilization secondary to inflammation, acute stress and/or illness.

While clinically seen, published data from the pediatric population are scarce and exist only for very ill populations. In a case series of 96 pediatric burn patients receiving parenteral nutrition, $46 \%$ required insulin. ${ }^{61}$ In extremely low birthweight, parenterally fed infants treated in a neonatal intensive care unit, more than $50 \%$ of them had persistent hyperglycemia in their first week of life. $^{62}$

\section{Management}

Management of drug-induced hyperglycemia should start by identifying risk factors, particularly those that may be modifiable. If a patient is considered to be at high risk for developing hyperglycemia, efforts should focus on prevention strategies. Depending on the clinical scenario, potential approaches include delaying therapy until the patient attains an age-appropriate weight for height, promoting regular physical activity, and ensuring a healthy diet. In addition, clinicians should, if feasible, prescribe medications with lower risk of hyperglycemia, and avoid combination of two or more diabetogenic drugs as clinically appropriate. Finally, protocols for monitoring hyperglycemia should be in place in hospitals and ambulatory practices using diabetogenic medications frequently.

Monitoring hyperglycemia in at-risk populations should include patient education on the signs and symptoms of diabetes as well as blood glucose monitoring at regular intervals. The frequency and method of monitoring blood glucoses should be tailored to the drug regimen and individual risk factors. For example, in ill patients who are receiving high doses of drugs associated with hyperglycemia (eg, induction chemotherapy for ALL), fasting blood glucoses every few days may be necessary. On the other hand, for patients who are on long-term therapy with a medication associated with increased weight and insulin resistance, a HbAlc every few months is a reasonable approach. It must be emphasized that the HbA1c value is not reliable in patients with rapid red blood cell turnover or who are receiving blood transfusions.

For standardization purposes, diabetes should be diagnosed following the criteria established by a recognized professional organization, such as the American Diabetes Association (ADA) or the International Society of Pediatric and Adolescent Diabetes (ISPAD). ${ }^{63}$ If the patient meets the criteria for diabetes, it is essential to conduct an individualized assessment of risk factors, including a thorough family and past medical history, review of all current medications, physical exam and determination of pancreatic islet autoantibodies' titers. Additional insight regarding the mechanism of hyperglycemia may be sought by obtaining stimulated insulin, C peptide levels and/or if islet autoantibodies if an autoimmune mechanism is suspected.

Treatment options for children with diabetes are limited. With very few drugs approved in the pediatric population, the concern of polypharmacy, and multiple comorbidities in the majority of patients who develop hyperglycemia, insulin remains the angular rock. Other approaches, such as metformin and dietary management can also be considered, particularly if the mechanism of hyperglycemia is related to insulin resistance and weight gain. In a small study of children with ALL and drug-induced hyperglycemia ( $\mathrm{n}=17), 70 \%$ of patients achieved glycemic control with metformin alone. ${ }^{65}$ Liraglutide may also be considered in certain cases of medication-induced hyperglycemia as it has been recently approved by the Food and Drug Administration for treatment of T2D in children 10 years of age or older. As mechanisms of drug-induced hyperglycemia are better understood and as more antidiabetic drugs are approved in the pediatric population, the tool kit will expand. Finally if clinically possible, a less diabetogenic regimen for the underlying illness should be considered.

The goals of treatment of drug-induced hyperglycemia are to eliminate symptoms, if present, to decrease glucose to a target range that prevents acute complications of hyperglycemia such as dehydration, electrolyte imbalances, or diabetic ketoacidosis, and to prevent long-term sequelae of diabetes. The benefits of euglycemia should be weighed against the risks of hypoglycemia, particularly when using insulin. Since the risks of hyperglycemia and hypoglycemia are different in the acutely ill compared 
with the stable outpatient setting, these will be discussed separately.

In the pediatric intensive care setting, hyperglycemia has been associated with poor outcomes. ${ }^{66}$ However, achieving tight glucose control is challenging as many patients have poor oral intake, if any, and, most importantly, they may not be able to recognize or communicate the symptoms of hypoglycemia, and therefore rely exclusively on glucose monitoring. Additionally, the target glucose range continues to be controversial as the benefit of tight blood glucose control on morbidity and mortality has been inconsistent. A single-center randomized control trial conducted in 700 critically ill infants and children in a pediatric intensive care setting showed improved short-term outcomes (ie, decreased length of stay, mortality and inflammation marker) at the expense of increased frequency of hypoglycemia in those with lower target blood glucose levels $(50-80 \mathrm{mg} / \mathrm{dL}$ in infants and $70-100 \mathrm{mg} / \mathrm{dL}$ in children) compared with the group with higher target blood glucose levels $(<215 \mathrm{mg} / \mathrm{dL}){ }^{67}$ In contrast, a recent multicenter trial that compared tight glucose control $(80-110 \mathrm{mg} / \mathrm{dL})$ with a higher glucose target $(150-180 \mathrm{mg} / \mathrm{dL})$ was stopped early due to low likelihood of benefit, and possibility of harm in the tight glucose control group. ${ }^{68}$ In this study, lengths of stay were similar in both groups, but the group with the lower glucose target had higher rates of hypoglycemia and higher rates of infection. Consequently, in the critically ill patients, it is reasonable to have a blood glucose target of $120-180 \mathrm{mg} / \mathrm{dL}$ and decrease it as the patient improves clinically and the risk of hypoglycemia decreases. These values continue to be arbitrary and may change as more data become available.

In the outpatient setting, tighter glucose control should be attempted. Children with T1D and T2D have increased risk of microvascular complications (retinopathy, nephropathy, neuropathy) and cardiovascular disease; and improved glycemic control decreases such risk. ${ }^{69}$ Even though there are no studies on long-term outcomes of microvascular and macrovascular disease in drug-induced diabetes, many of these patients (eg, transplant patients, childhood cancer survivors) are already at higher risk of cardiovascular disease, and therefore preventing any additional potential damage is important. ${ }^{70}$ One of the drawbacks of tighter glucose control is increase in the burden of care and hence the potential decrease in quality of life with frequent insulin administration and blood glucose monitoring. However, if hyperglycemia is expected to be long-standing, and the patient is otherwise stable, glucose and HbAlc goals set by ADA or ISPAD should be followed. ${ }^{71} 72$

\section{CONCLUSIONS}

Medication-induced hyperglycemia usually originates from insulin resistance and/or decreased insulin secretion. Many of the molecular mechanisms for the changes in insulin secretion/action as well as the basis for the variability between patients are poorly understood. In the majority, although not all, of the cases, host susceptibility and drug-drug amplification effects are identified. All patients with drug-induced hyperglycemia should have a thorough evaluation of risk factors and possible drug interactions. Consideration should be given to addressing modifiable risk factors and using less diabetogenic drug regimens in at-risk patients or patients who have hyperglycemia. Treatment should be directed to normalizing blood glucoses while preventing hypoglycemia. Insulin remains the cornerstone of treatment of drug-induced hyperglycemia in children, as other treatment strategies are limited in the pediatric population.

This area represents a growing research opportunity as many unknowns remain, from molecular mechanisms of drug-induced hyperglycemia, to incidence of hyperglycemia in the pediatric population, and to better elucidation of risk factors. The identification of genetic risk factors may provide an explanation for those children who develop hyperglycemia but do not present manifestations of the metabolic syndrome phenotype. Collaborative, multi-institutional databases of cases of medicationinduced hyperglycemia would facilitate an exchange of information among clinicians and researchers. Finally, clinical trials on the pediatric population with druginduced hyperglycemia are needed.

Contributors JV-C and MT wrote the manuscript draft. MA and MJR reviewed and edited the manuscript draft. SKL critically revised the manuscript draft.

Funding The authors have not declared a specific grant for this research from any funding agency in the public, commercial or not-for-profit sectors.

Competing interests None declared.

Patient consent for publication Not required.

Provenance and peer review Not commissioned; externally peer reviewed.

Data availability statement All data relevant to the study are included in the article.

Open access This is an open access article distributed in accordance with the Creative Commons Attribution Non Commercial (CC BY-NC 4.0) license, which permits others to distribute, remix, adapt, build upon this work non-commercially, and license their derivative works on different terms, provided the original work is properly cited, appropriate credit is given, any changes made indicated, and the use is non-commercial. See: http://creativecommons.org/licenses/by-nc/4.0/.

ORCID iD

Mustafa Tosur http://orcid.org/0000-0002-2111-271X

\section{REFERENCES}

1 Byun DJ, Wolchok JD, Rosenberg LM, et al. Cancer immunotherapy - immune checkpoint blockade and associated endocrinopathies. Nat Rev Endocrinol 2017;13:195-207.

2 Chen J, Huang X-F, Shao R, et al. Molecular mechanisms of antipsychotic drug-induced diabetes. Front Neurosci 2017;11:643.

3 Chakkera HA, Kudva Y, Kaplan B. Calcineurin inhibitors: pharmacologic mechanisms impacting both insulin resistance and insulin secretion leading to glucose dysregulation and diabetes mellitus. Clin. Pharmacol. Ther. 2017;101:114-20.

4 Belcastro V, D'Egidio C, Striano P, et al. Metabolic and endocrine effects of valproic acid chronic treatment. Epilepsy Res 2013;107:1-8.

5 Gosmanov AR, Umpierrez GE. Management of hyperglycemia during enteral and parenteral nutrition therapy. Curr Diab Rep 2013;13:155-62.

6 Baillargeon J, Langevin A-M, Mullins J, et al. Transient hyperglycemia in Hispanic children with acute lymphoblastic leukemia. Pediatr Blood Cancer 2005;45:960-3. 
7 Perez A, Jansen-Chaparro S, Saigi I, et al. Glucocorticoid-Induced hyperglycemia. J Diabetes 2014;6:9-20.

8 Egler R, Ahuja S, Matloub Y. L-Asparaginase in the treatment of patients with acute lymphoblastic leukemia. J Pharmacol Pharmacother 2016;7:62-71.

9 Roberson JR, Raju S, Shelso J, et al. Diabetic ketoacidosis during therapy for pediatric acute lymphoblastic leukemia. Pediatr Blood Cancer 2008;50:1207-12.

10 Heisel O, Heisel R, Balshaw R, et al. New onset diabetes mellitus in patients receiving calcineurin inhibitors: a systematic review and meta-analysis. Am J Transplant 2004;4:583-95.

11 Greenspan LC, Gitelman SE, Leung MA, et al. Increased incidence in post-transplant diabetes mellitus in children: a case-control analysis. Pediatric Nephrology 2002;17:1-5.

12 mTOR VB. And cardiovascular diseases: diabetes mellitus. Transplantation 2017.

13 Johnston O, Rose CL, Webster AC, et al. Sirolimus is associated with new-onset diabetes in kidney transplant recipients. JASN 2008;19:1411-8.

14 Rogers J, Ashcraft EE, Baliga PK, et al. Long-Term outcome of sirolimus rescue in Kidney-Pancreas transplantation. Transplant Proc 2004;36:1058-60.

15 Bayés B, Pastor MC, Lauzurica R, et al. Do anti-CD25 monoclonal antibodies potentiate posttransplant diabetes mellitus? Transplant Proc 2007;39:2248-50.

16 Prasad N, Gurjer D, Bhadauria D, et al. Is basiliximab induction, a novel risk factor for new onset diabetes after transplantation for living donor renal allograft recipients? Nephrology 2014;19:244-50.

17 de Filette JMK, Pen JJ, Decoster L, et al. Immune checkpoint inhibitors and type 1 diabetes mellitus: a case report and systematic review. Eur J Endocrinol 2019;181:363-74.

18 Verrotti A, Manco R, Agostinelli S, et al. The metabolic syndrome in overweight epileptic patients treated with valproic acid. Epilepsia 2010;51:268-73.

19 Treasure T, Toseland PA. Hyperglycaemia due to phenytoin toxicity. Arch Dis Child 1971;46:563-4.

20 Witthayapraphakorn L, Srilanchakon K, Sahakitrungruang T, et al. Phenytoin-Induced dysglycemia in a child. Pediatrics International 2017;59:1022-3.

21 Mimouni-Bloch A, Mimouni M. Clonidine-Induced hyperglycemia in a young diabetic girl. Ann Pharmacother 1993;27.

22 Nishina K, Mikawa K, Maekawa N, et al. Effects of oral clonidine premedication on plasma glucose and lipid homeostasis associated with exogenous glucose infusion in children. Anesthesiology 1998;88:922-7.

23 Fathallah N, Slim R, Larif S, et al. Drug-Induced hyperglycaemia and diabetes. Drug Saf 2015;38:1153-68.

24 Pramyothin $\mathrm{P}$, Khaodhiar L. Type 2 diabetes in children and adolescents on atypical antipsychotics. Curr Diab Rep 2015;15:53.

25 Bobo WV, Cooper WO, Stein CM, et al. Antipsychotics and the risk of type 2 diabetes mellitus in children and youth. JAMA Psychiatry 2013;70:1067-75

26 Elliott WJ, Meyer PM. Incident diabetes in clinical trials of antihypertensive drugs: a network meta-analysis. The Lancet 2007;369:201-7

27 Duarte JD, Cooper-DeHoff RM. Mechanisms for blood pressure lowering and metabolic effects of thiazide and thiazide-like diuretics. Expert Rev Cardiovasc Ther 2010;8:793-802.

28 Bangalore S, Parkar S, Grossman E, et al. A meta-analysis of 94,492 patients with hypertension treated with beta blockers to determine the risk of new-onset diabetes mellitus. Am J Cardiol 2007;100:1254-62.

29 Rizos CV, Elisaf MS. Antihypertensive drugs and glucose metabolism. World J Cardiol 2014;6:517-30.

30 Yildirim SV, Azak E, Varan B, et al. Unusual and early hyperglycemia following amiodarone infusion in two infants. Pediatr Cardiol 2005;26:715-6.

31 Pollak PT, Sami M. Acute necrotizing pneumonitis and hyperglycemia after amiodarone therapy. Case report and review of amiodarone-associated pulmonary disease. Am J Med 1984;76:935-9.

32 Cohen MH, Nihill MR. Postoperative ketotic hyperglycemia during prostaglandin E1 infusion in infancy. Pediatrics 1983;71:842-4.

33 Navarese EP, Buffon A, Andreotti F, et al. Meta-Analysis of impact of different types and doses of statins on new-onset diabetes mellitus. Am J Cardiol 2013;111:1123-30.

34 Cederberg $\mathrm{H}$, Stančáková A, Yaluri N, et al. Increased risk of diabetes with statin treatment is associated with impaired insulin sensitivity and insulin secretion: a 6 year follow-up study of the METSIM cohort. Diabetologia 2015;58:1109-17.
35 Canas JA, Ross JL, Taboada MV, et al. A randomized, double blind, placebo-controlled pilot trial of the safety and efficacy of atorvastatin in children with elevated low-density lipoprotein cholesterol (LDL-C) and type 1 diabetes. Pediatr Diabetes 2015;16:79-89.

36 Chang AM, Smith MJ, Galecki AT, et al. Impaired beta-cell function in human aging: response to nicotinic acid-induced insulin resistance. J Clin Endocrinol Metab 2006;91:3303-9.

37 Jørgensen JOL, Krag M, Jessen N, et al. Growth hormone and glucose homeostasis. Horm Res Paediatr 2004;62:51-5.

38 Cutfield WS, Wilton $\mathrm{P}$, Bennmarker $\mathrm{H}$, et al. Incidence of diabetes mellitus and impaired glucose tolerance in children and adolescents receiving growth-hormone treatment. The Lancet 2000;355:610-3.

39 Bonfig W, Molz K, Woelfle J, et al. Metabolic safety of growth hormone in type 1 diabetes and idiopathic growth hormone deficiency. J Pediatr 2013;163:1095-8.

40 Sitruk-Ware R, Nath A. Metabolic effects of contraceptive steroids. Rev Endocr Metab Disord 2011;12:63-75.

41 Lopez LM, Grimes DA, Schulz KF, et al. Steroidal contraceptives: effect on carbohydrate metabolism in women without diabetes mellitus. Cochrane Database Syst Rev 2014;16.

42 Dougherty PP, Lee SC, Lung D, et al. Evaluation of the use and safety of octreotide as antidotal therapy for sulfonylurea overdose in children. Pediatr Emerg Care 2013;29:292-5.

43 Testoni D, Hornik CP, Neely ML, et al. Safety of octreotide in hospitalized infants. Early Hum Dev 2015;91:387-92.

44 Pai V, Porter K, Ranalli M. Octreotide acetate is efficacious and safe in children for treating diarrhea due to chemotherapy but not acute graft versus host disease. Pediatr Blood Cancer 2011;56:45-9.

45 Aljazairi AS, Bhuiyan TA, Alwadai AH, et al. Octreotide use in post-cardiac surgery chylothorax: a 12-year perspective. Asian Cardiovasc Thorac Ann 2017;25:6-12.

46 El Ghandour S, Azar ST. Dysglycemia associated with quinolones. Prim Care Diabetes 2015;9:168-71.

47 Lamb T. Tequin Was Withdrawn From U.S. Market "For Reasons Of Safety Or Effectiveness"; 2008.

48 Vinh H, Anh VTC, Anh ND, et al. A multi-center randomized trial to assess the efficacy of gatifloxacin versus ciprofloxacin for the treatment of shigellosis in Vietnamese children. PLoS Negl Trop Dis 2011;5:e1264.

49 Shen M, Orwoll ES, Conte JE, et al. Pentamidine-induced pancreatic beta-cell dysfunction. Am J Med 1989;86:726-8.

50 Assan R, Perronne C, Assan D, et al. Pentamidine-Induced derangements of glucose homeostasis: determinant roles of renal failure and drug accumulation: a study of 128 patients. Diabetes Care 1995;18:47-55.

51 Wang JJ, Freeman Al, Gaeta JF, et al. Unusal complications of pentamidine in the treatment of Pneumocystis carinii pneumonia. $J$ Pediatr 1970;77:311-4.

52 Woerle HJ, Mariuz PR, Meyer C, et al. Mechanisms for the deterioration in glucose tolerance associated with HIV protease inhibitor regimens. Diabetes 2003;52:918-25.

53 Behrens G, Dejam A, Schmidt H, et al. Impaired glucose tolerance, beta cell function and lipid metabolism in HIV patients under treatment with protease inhibitors. AIDS 1999;13:F63-70.

54 Geffner ME, Patel K, Miller TL, et al. Factors associated with insulin resistance among children and adolescents perinatally infected with HIV-1 in the pediatric HIV/AIDS cohort study. Horm Res Paediatr 2011:76:386-91.

55 Hardy H, Esch LD, Morse GD. Glucose disorders associated with HIV and its drug therapy. Ann Pharmacother 2001;35:343-51.

56 Smith AP, Banks J, Buchanan K, et al. Mechanisms of abnormal glucose metabolism during the treatment of acute severe asthma. $Q$ J Med 1992;82:71-80.

57 Dawson KP, Penna AC, Manglick P. Acute asthma, salbutamol and hyperglycaemia. Acta Paediatr 1995;84:305-7.

58 König P, Goldstein D, Poehlmann M, et al. Effect of nebulized albuterol on blood glucose in patients with diabetes mellitus with and without cystic fibrosis. Pediatr Pulmonol 2005;40:105-8.

59 Kearney TE, Manoguerra AS, Curtis GP. Theophylline toxicity and the beta-adrenergic system. Ann Intern Med 1985;102:766-9.

60 Shannon M, Lovejoy FH. Effect of acute versus chronic intoxication on clinical features of theophylline poisoning in children. $J$ Pediatr 1992;121:125-30.

61 Dylewksi ML, Baker M, Prelack K, et al. The safety and efficacy of parenteral nutrition among pediatric patients with burn Injuries* Pediatric Critical Care Medicine 2013;14:e120-5.

62 Hays SP, Smith EO, Sunehag AL. Hyperglycemia is a risk factor for early death and morbidity in extremely low birth-weight infants. Pediatrics 2006;118:1811-8. 
63 American Diabetes Association. 2. Classification and Diagnosis of Diabetes: Standards of Medical Care in Diabetes-2019. Diabetes Care 2019;42:S13-28.

64 Mayer-Davis EJ, Kahkoska AR, Jefferies C, et al. ISPAD clinical practice consensus guidelines 2018: definition, epidemiology, and classification of diabetes in children and adolescents. Pediatr Diabetes 2018;19:7-19.

65 Bostrom B, Uppal P, Chu J, et al. Safety and efficacy of metformin for therapy-induced hyperglycemia in children with acute Iymphoblastic leukemia. J Pediatr Hematol Oncol 2013;35:504-8.

66 Hirshberg E, Larsen G, Van Duker H. Alterations in glucose homeostasis in the pediatric intensive care unit: hyperglycemia and glucose variability are associated with increased mortality and morbidity. Pediatr Crit Care Med 2008;9:361-6.

67 Vlasselaers D, Milants I, Desmet L, et al. Intensive insulin therapy for patients in paediatric intensive care: a prospective, randomised controlled study. The Lancet 2009;373:547-56.
68 Agus MSD, Wypij D, Hirshberg EL, et al. Tight glycemic control in critically ill children. N Engl J Med 2017;376:729-41.

69 Donaghue KC, Marcovecchio ML, Wadwa RP, et al. ISPAD clinical practice consensus guidelines 2018: microvascular and macrovascular complications in children and adolescents. Pediatr Diabetes 2018;19:262-74.

70 Scholz-Kreisel P, Spix C, Blettner M, et al. Prevalence of cardiovascular late sequelae in long-term survivors of childhood cancer: a systematic review and meta-analysis. Pediatr Blood Cancer 2017;64.

71 American Diabetes Association. 13. Children and Adolescents: Standards of Medical Care in Diabetes-2019. Diabetes Care 2019;42:S148-64.

72 DiMeglio LA, Acerini CL, Codner E, et al. ISPAD clinical practice consensus guidelines 2018: glycemic control targets and glucose monitoring for children, adolescents, and young adults with diabetes. Pediatr Diabetes 2018;19:105-14. 